\title{
Study of the seismic response of reinforced concrete isolated elevated water tanks
}

\author{
V. I. Fernández-Dávila, F. Gran \& P. Baquedano \\ School of Civil Engineering at Civil Works, Central University, \\ Santa Isabel, Chile
}

\begin{abstract}
This investigation carries out the seismic response of parametric elastic models of reinforced concrete isolated elevated water tanks. From the study of the physical and geometric variables that characterize elevated water tanks it was possible to define parametric models with the purpose of obtaining a wide representative family of structures. The parameters were grouped in the following form: a) elevated tank: ratio of heights, ratio of slenderness, ratio of diameters, ratio diameter-thickness, and ratio water mass-structure mass, b) isolation system: ratio of slenderness, horizontal and vertical stiffness, c) water: the water-structure interaction effect is modeled using the mechanical analogy proposed by Housner.

This special type of continuous structure, similar to an inverted pendulum, has been discretized according to the lumped mass criterion and the support structure of the tower was partitioned in ten one-dimensional elements. As seismic loads were applied the design spectrum of accelerations were used as recommended by the Chilean code NCh 2745 Of.2003, respectively.

The maximum responses were obtained for the lateral displacements, the shear forces and bending moments. The sensitivity analysis of the structural models of isolated elevated water tanks allowed us to observe that the maximum bending moments and the maximum shear forces are equivalent to the eighth part of the maximum responses obtained in a similar fixed-base elevated water tank, and that the relative lateral displacements are lower that $0.2 \%$, reducing the deformations in the structure significantly.
\end{abstract}

Keywords: elevated water tanks, dynamic of structures, seismic loads, seismic base isolation, lateral displacements, shear forces, bending moments. 


\section{Introduction}

Chile has suffered devastating seismic effects of great magnitude on many occasions, which resulted in serious consequences such as the loss of human lives and resources. On the basis of past experiences, the repetition of this phenomenon in the future must be thought of as a certain possibility, incurring the same catastrophic effects that have occurred in the past and maybe in higher proportions. Having taken this consideration into account, it is necessary to prepare to face new menaces of this nature, adopting ways to avoid or minimize the effects of earthquakes that could occur in the future [4, 9].

Elevated water tanks are industrial structures built for the purpose of maintaining the water supply. There are researches on this special kind of continuous structure that has its bases fixed and isolated [11]. The application of seismic isolation systems in other parts of the world has concentrated its efforts on the research of conventional structures such as buildings, that results in very attractive research about its application in this special kind of continuous structure generally considered as rigid [9]. Indeed, in the last years, the seismic isolation system has seen an increased application on buildings in countries that have high seismic risks (Japan, United States, Italy, Canada, New Zealand). Its effectiveness was proven during the occurrence of important earthquakes such as Northridge (USA, 1994) and the Kobe (Japan, 1995), due to the fact that these areas presented an important number of structures designed with frictional and elastomeric isolation systems [10].

The objective of this investigation is to study the seismic responses of this special kind of "compound structure" with the purpose of understanding the structural behaviour due to seismic action.

\section{Methodology}

\subsection{Type of structure}

A reinforced concrete elevated tank of drinkable water which had a flexible connection between the superstructure and the foundation, denominated seismic isolator, was analyzed. These mechanisms (table 1) work in an elastic range and consist basically of a collection of thin rubber plates interspersed with steel plates which are stuck to the rubber with an adhesive gum and then are subjected to a vulcanisation process. A resistant element of a low horizontal rigidity and high vertical rigidity was obtained as a result, succeeding to uncouple the structure from the seismic movements of the land. Twelve isolators that are equidistant to each other and located in the perimeter of the structure of support, were used (figs. 1, 2).

The kind of superstructure used is the elevated water tank made of reinforced concrete as the composite. This kind of structure presents a support base or shaft and in its higher area a tank or barrel, both elements are of transversal, circular section. 
Earthquake Resistant Engineering Structures VI 119

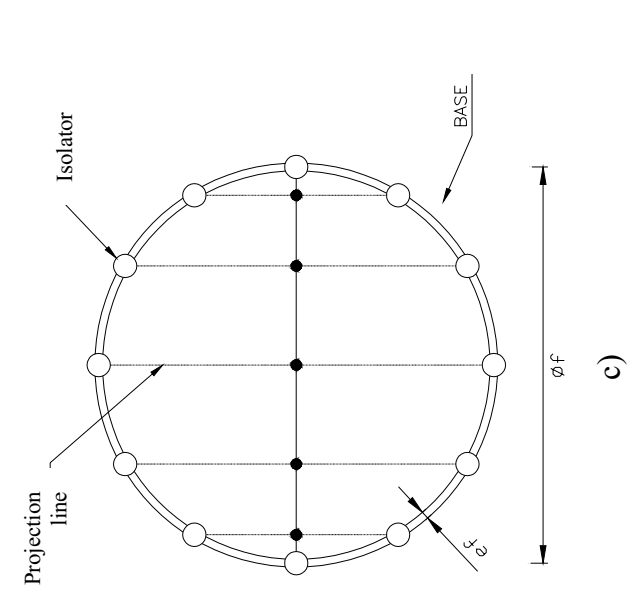

4
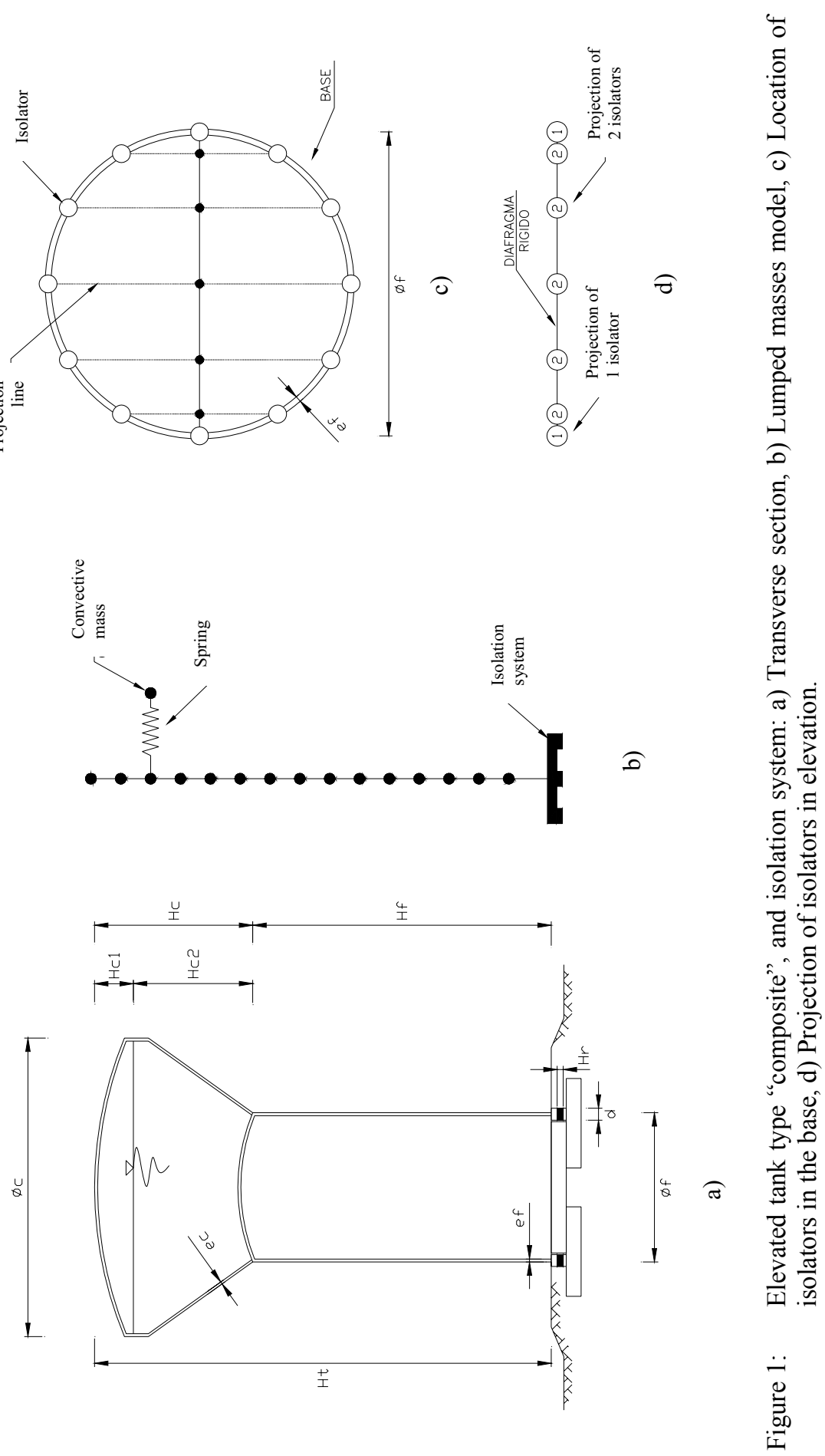

WIT Transactions on The Built Environment, Vol 93, (C) 2007 WIT Press www.witpress.com, ISSN 1743-3509 (on-line) 
This choice was performed from a sensitivity analysis of the tanks of this kind constructed in the central area of Chile and its capacity to support great water masses inside. The kind of isolator considered on the research is the high damping isolator (HDR) [10], owing to the fact of its high capacity to dissipate the energy that comes from the seismic movement of the land, preventing this energy from being totally absorbed by superstructure.

For the sensitivity analysis, eight real tanks that fulfill the required geometry have been found. These tanks constitute the pattern database, identifying the more relevant geometric and physic relevant features (tables 2, 3) from the study of each one of them. Geometric properties were considered such as (fig. 1): $\mathrm{H}_{\mathrm{t}}$, $\mathrm{H}_{\mathrm{c}}, \mathrm{H}_{\mathrm{f}}$, which are the total heights of the tank and the structure of support, respectively; in addition, $\mathrm{e}_{\mathrm{f}}, \mathrm{e}_{\mathrm{c}}$, are the thicknesses of the structure of support and the tank; $\phi_{\mathrm{f}}, \phi_{\mathrm{c}}$, are the diameter of the structure of support and the tank; and $\mathrm{H}_{\mathrm{c} 1}$ and $\mathrm{H}_{\mathrm{c} 2}$, are the fixed and variable height of the tank, respectively. The modeling of the tank, such as structures of the reversed pendulum kind, is shown in table 3 and consists of verifying more than $50 \%$ of the total weight which is found in the superior level [7].

Table 1: $\quad$ Characteristics of the isolators.

\begin{tabular}{|c|c|c|c|c|}
\hline Description & Unit & Reinforced rubber & No reinforced rubber & Steel \\
\hline IRHD $^{1}$ & & 45 & 65 & 100 \\
$\sigma_{\mathrm{t}}$ & $\mathrm{MN} / \mathrm{m}^{2}$ & 28 & 21 & 420 \\
$\sigma_{\mathrm{u}}$ & $\%$ & 680 & 420 & 40 \\
$\mathrm{E}$ & $\mathrm{MN} / \mathrm{m}^{2}$ & 1,9 & 5,9 & 210.000 \\
$\mathrm{G}$ & $\mathrm{MN} / \mathrm{m}^{2}$ & 0,54 & 1,37 & 81.000 \\
$\mathrm{k}$ & $\mathrm{MN} / \mathrm{m}^{2}$ & 1.000 & 1.200 & 176.000 \\
$\mathrm{v}$ & & 0,4997 & 0,4997 & 0,29 \\
Resilience & $\%$ & 80 & 60 & 100 \\
$\mathrm{~V}_{\mathrm{s}}$ & $\mathrm{m} / \mathrm{s}$ & 37 & 37 & 5.000 \\
\hline
\end{tabular}

${ }^{1}$ International Rubber Hardness.

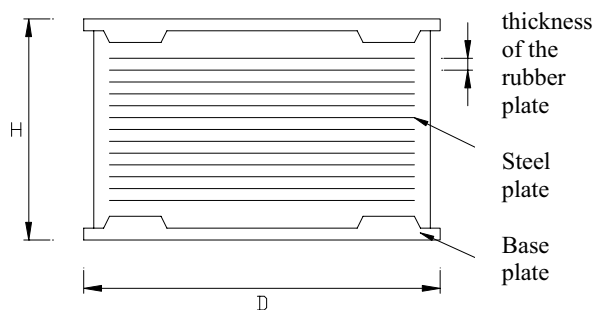

Figure 2: $\quad$ Elastomeric seismic isolator. 
Table 2: $\quad$ Characteristics of the real tanks and seismic data.

\begin{tabular}{|c|c|c|c|c|c|c|c|c|c|c|c|c|c|c|}
\hline \multirow{2}{*}{$\mathrm{N}^{\mathrm{o}}$} & \multirow{2}{*}{ Tank } & \multirow{2}{*}{$\begin{array}{c}\text { Capacity } \\
\left(\mathrm{m}^{3}\right)\end{array}$} & \multirow{2}{*}{\begin{tabular}{|l|}
$\mathrm{H}_{\mathrm{t}}$ \\
$(\mathrm{m})$ \\
\end{tabular}} & \multirow{2}{*}{$\begin{array}{l}\mathrm{H}_{\mathrm{c}} \\
(\mathrm{m})\end{array}$} & \multirow{2}{*}{$\begin{array}{c}\mathrm{H}_{\mathrm{f}} \\
(\mathrm{m})\end{array}$} & \multirow{2}{*}{$\begin{array}{c}\phi_{\mathrm{c}} \\
(\mathrm{m})\end{array}$} & \multirow{2}{*}{$\begin{array}{c}\phi_{\mathrm{f}} \\
(\mathrm{m})\end{array}$} & \multirow{2}{*}{$\begin{array}{l}\mathrm{e}_{\mathrm{c}} \\
(\mathrm{m})\end{array}$} & \multirow{2}{*}{$\begin{array}{c}e_{f} \\
(\mathrm{~m})\end{array}$} & \multirow{2}{*}{$\mid \begin{array}{l}\mathrm{H}_{\mathrm{c} 1} \\
(\mathrm{~m})\end{array}$} & \multirow{2}{*}{$\begin{array}{l}\mathrm{H}_{\mathrm{c} 2} \\
(\mathrm{~m})\end{array}$} & \multicolumn{3}{|c|}{ Seismic data } \\
\hline & & & & & & & & & & & & Zone & Soil & $\xi(\%)$ \\
\hline 1 & Pontigo-Buin & 2.000 & 31,3 & 10,1 & 21,2 & 23,8 & 12 & 0,2 & 0,25 & 2,1 & 8,0 & 2 & II & 5 \\
\hline 2 & Linderos & 2.000 & 38,3 & 10,1 & 28,2 & 23,8 & 12 & 0,2 & 0,25 & 2,1 & 8,0 & 2 & II & 5 \\
\hline 3 & Paine & 1.000 & 35,8 & 6,8 & 29,0 & 19,0 & 12 & 0,2 & 0,20 & 1,7 & 5,2 & 2 & II & 5 \\
\hline 4 & Los Tilos & 1.500 & 29,8 & 8,8 & 21,0 & 19,0 & 12 & 0,2 & 0,20 & 3,6 & 5,2 & 2 & II & 5 \\
\hline 5 & Estadio-Estación Buin & 1.500 & 32,8 & 8,8 & 24,0 & 19,0 & 12 & 0,2 & 0,20 & 3,6 & 5,2 & 2 & II & 5 \\
\hline 6 & Melipilla & 500 & 30,3 & 5,3 & 25,0 & 12,9 & 9 & 0,2 & 0,20 & 1,6 & 3,7 & 3 & III & 5 \\
\hline 7 & El Monte & 500 & 25,3 & 5,3 & 20,0 & 12,9 & 9 & 0,2 & 0,20 & 1,6 & 3,7 & 3 & III & 5 \\
\hline 8 & El Trébol & 2000 & 38,3 & 10,1 & 28,2 & 24,2 & 12 & 0,2 & 0,25 & 2,3 & 7,8 & 2 & II & 5 \\
\hline
\end{tabular}

Table 3: $\quad$ Weights of the elevated water tanks $(\mathrm{kN})$.

\begin{tabular}{|l|cccc|c|c|c|}
\hline \multicolumn{1}{|c|}{ Tank } & $\mathrm{W}_{\text {fuste }}$ & $\mathrm{W}_{\text {cuba }}$ & $\mathrm{W}_{\mathrm{t}}$ & $\mathrm{W}_{\mathrm{f}}$ & $\mathrm{W}_{\text {total }}$ & $\mathrm{W}_{\text {sup }}=\mathrm{W}_{\text {cuba }}+\mathrm{W}_{\mathrm{H} 2 \mathrm{O}}$ & $\mathrm{W}_{\text {sup }} / \mathrm{W}_{\text {total }}(\%)$ \\
\hline Pontigo-Buin & 5.000 & 5.390 & 10.390 & 20.000 & 30.390 & 25.390 & 83,6 \\
Linderos & 6.650 & 5.390 & 12.040 & 20.000 & 32.040 & 25.390 & 79,3 \\
Paine & 5.470 & 3.410 & 8.880 & 10.000 & 18.880 & 13.410 & 71,0 \\
Buin & 3.960 & 3.980 & 7.940 & 15.000 & 22.940 & 18.980 & 82,7 \\
Estadio Buin & 4.520 & 3.980 & 8.500 & 15.000 & 23.500 & 18.980 & 80,8 \\
Melipilla & 3.530 & 1.750 & 5.280 & 5.000 & 10.280 & 6.750 & 65,6 \\
El Monte & 2.830 & 1.750 & 4.580 & 5.000 & 9.580 & 6.750 & 70,5 \\
El Trébol & 6.650 & 5.520 & 12.170 & 20.000 & 32.170 & 25.520 & 79,3 \\
\hline
\end{tabular}

\subsection{Fluid-structure interaction}

The fluid-structure interaction was determined using the equivalent mechanical model proposed by professor Housner. Effectively, it proposes that the motion of the total mass of water can be represented in the following way: a) a solidary mass to the tank, called fixes or impulsive mass $\left(\mathrm{M}_{0}\right)$; and $\left.\mathrm{b}\right)$ a mass that represents the phenomenon of surge of water, named movable or convective mass $\left(\mathrm{M}_{1}\right)$ and connected to the walls of the tank by total stiffness K [5]. Eqs. (1) to (6) allow us to evaluate the impulsive and convective masses, the stiffness of the spring, the water vibration period, and the location of these masses measured from the base of the tank.

$$
\frac{\mathrm{M}_{0}}{\mathrm{M}_{\mathrm{F}}}=\frac{\operatorname{Tanh}\left(\frac{\sqrt{3}}{2} \cdot \frac{\mathrm{D}}{\mathrm{H}}\right)}{\frac{\sqrt{3}}{2} \cdot \frac{\mathrm{D}}{\mathrm{H}}}, \quad \frac{\mathrm{M}_{1}}{\mathrm{M}_{\mathrm{F}}}=\frac{363}{512} \cdot \frac{\operatorname{Tanh}\left(\sqrt{13.5} \cdot \frac{\mathrm{H}}{\mathrm{D}}\right)}{\sqrt{13.5 \cdot \frac{\mathrm{H}}{\mathrm{D}}}}
$$




$$
\begin{array}{r}
\frac{H \cdot K}{\mathrm{~W}_{\mathrm{F}}}=\frac{45}{2} \cdot\left(\frac{\mathrm{M}_{1}}{\mathrm{M}_{\mathrm{F}}}\right)^{2} \cdot\left(\frac{\mathrm{H}}{\mathrm{D}}\right)^{2}, \quad \mathrm{~T}_{\mathrm{a}}=2 \pi \cdot \sqrt{\frac{\mathrm{M}_{1}}{\mathrm{~K}}} \\
\mathrm{~h}_{0}=\frac{3}{8} \cdot \mathrm{H} \cdot\left[1+\alpha \cdot\left(\frac{\mathrm{M}_{\mathrm{F}}}{\mathrm{M}_{0}}-1\right)\right], \mathrm{h}_{1}=\mathrm{H} \cdot\left[1-\frac{\operatorname{Cosh}\left(\sqrt{13.5} \cdot \frac{\mathrm{H}}{\mathrm{D}}\right)-\beta}{\sqrt{13.5} \cdot \frac{\mathrm{H}}{\mathrm{D}} \cdot \operatorname{Senh}\left(\sqrt{13.5} \cdot \frac{\mathrm{H}}{\mathrm{D}}\right)}\right]
\end{array}
$$

where $\mathrm{M}_{\mathrm{F}}$, and $\mathrm{W}_{\mathrm{F}}$, are the total mass and weight of the water; $\alpha$ and $\beta$ are dependent variables of the pressures of the walls; $h_{0}$, and $h_{1}$, are the heights of the impulsive and convective masses, both measured with respect to the bottom of the tank; $T_{a}$, fundamental period of vibration of the convective mass; $H$ and $D$, are the height and diameter of the tank, respectively. The values considered for this study were $\alpha=0$, and $\beta=1$ [5], because the pressures of the water stored on the walls of the container are considered. In the present study the height $\mathrm{H}$ is equal to the height $\mathrm{H}_{\mathrm{c}}$, and the diameter $\mathrm{D}$ is equal to $\phi_{\mathrm{c}}$ of the analyzed model (fig. 1a). In addition, $\mathrm{W}_{\mathrm{f}}$ is equal to $\mathrm{W}_{\mathrm{H} 2 \mathrm{O}}$.

\subsection{Parametric analysis of the structure}

From the study of the most relevant elastic characteristics that determine the behavior of the eight elevated water tanks defined in the database, it was possible to select ten parameters of interest that, if combined suitably, allow us to represent an ample family of this type of structure $[1,3,4,9]$. The parameters are as follows:

- $\quad$ (RH) Height ratio (tank - structure of support)

$=\mathrm{H}_{\mathrm{c}} / \mathrm{H}_{\mathrm{f}}$

- $\quad(\mathrm{RD})$ Diameter ratio (tank - structure of support)

$=\phi_{\mathrm{c}} / \phi_{\mathrm{f}}$

- $\quad(\mathrm{RR})$ Height - Diameter ratio

$=\mathrm{RH} / \mathrm{RD}$

- (HD) Slenderness ratio

$=\mathrm{H}_{\mathrm{t}} / \phi_{\mathrm{f}}$

- $\left(\mathrm{DE}_{\mathrm{c}}\right)$ Diameter ratio - thickness in the tank

$=\phi_{\mathrm{c}} / \mathrm{e}_{\mathrm{c}}$

- $\left(\mathrm{DE}_{\mathrm{f}}\right)$ Diameter ratio - thickness in the structure of support

$=\phi_{\mathrm{f}} / \mathrm{e}_{\mathrm{f}}$

- $\quad\left(\mathrm{RD}_{\mathrm{e}}\right)$ Diameter ratio-thickness

$=\mathrm{DE}_{\mathrm{c}} / \mathrm{DE}_{\mathrm{f}}$

- Mass ratio

- $\left(\mathrm{RH}_{\mathrm{c}}\right)$ Height ratio in the cube

- $\left(\mathrm{RH}_{\mathrm{a}}\right)$ Slenderness ratio of isolator

$=\mathrm{M}_{\mathrm{H} 2 \mathrm{O}} / \mathrm{M}_{\mathrm{t}}$

$=\mathrm{H}_{\mathrm{c} 1} / \mathrm{H}_{\mathrm{c}}$

$=\mathrm{H}_{\mathrm{r}} / \mathrm{d}$

Table 4: $\quad$ Values adopted for the parameters and number of studied cases.

\begin{tabular}{|c|c|c|c|c|c|c|c|c|c|c|}
\hline \multirow{2}{*}{ Id } & \multicolumn{4}{|c|}{ Tank } & Isolator & \multicolumn{3}{c|}{ Seismic } & \multirow{2}{*}{$\begin{array}{c}\text { N of total } \\
\text { cases }\end{array}$} \\
\cline { 2 - 11 } & $\mathrm{RR}$ & $\mathrm{HD}$ & $\mathrm{RD}_{\mathrm{e}}$ & $\mathrm{RH}_{\mathrm{c}}$ & $\mathrm{RM}$ & $\mathrm{RH}_{\mathrm{a}}$ & Soil & Zona & $\xi(\%)$ & \\
\hline 1 & 0,10 & 2,4 & 1,0 & 0,2 & 0,9 & 0,35 & 2 & & & \\
2 & 0,21 & 2,9 & 2,0 & 0,4 & 1,5 & 0,50 & 3 & 2 & 5 & 972 \\
3 & 0,36 & 3,2 & 2,7 & --- & 2,0 & 1,00 & --- & & & \\
\hline
\end{tabular}

---Value does not exist. 
Table 4 shows the geometric and seismic parameters considered in this study, as well as the values assigned to each one of them. These values were obtained from the analysis of sensitivity of the values adopted by each parameter of the eight structures of the database pattern. From this new database, a family of 972 elevated water tank structures could be generated.

\subsection{Sensitive analysis}

A sensitivity analysis was made in which the responses of a tank modeled by finite elements (MEF) and another one modeled by the criterion of lumped masses were compared (MC), in which the structure of support was discretized in 10 elements and the tank in five elements, both being of frame type [2]. The responses that were compared were the periods of vibration, the lateral displacements, the shear forces, and bending moments. The tank modeled by finite elements took control of elements type shells [2] of size $1 \times 1 \mathrm{~m}^{2}$.

The maximum errors found were: $2,3 \%$ in the periods of vibration, $8.8 \%$ in the lateral displacements, $6.6 \%$ in the basal shear forces, and $4.3 \%$ at the bending moments.

It was observed that the responses determined with criterion MC are greater than the responses obtained by MEF. This comparison was made on an empty and a full water elevated tank, considering, in addition, situations of isolated base and fixed $[1,4]$.

\subsection{Design spectrum}

The seismic load that was used corresponded to the design spectrum of the NCh 2745 Of. 2003 code [8]. In this norm is the type of elastic spectrum, which must be reduced by the factor of reduction $\mathrm{R}$ that is indicated in the code of industrial structures NCh 2369 Of. 2002 [7]. This design spectrum (fig. 3) depends on as much the seismic zone as the type of ground on which the structure is founded.

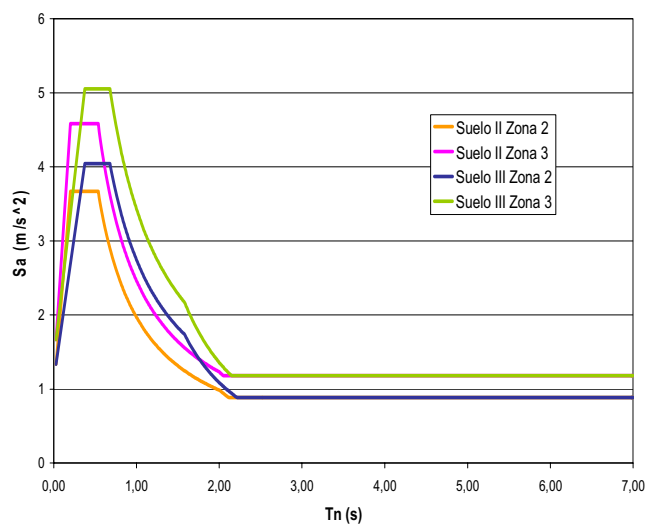

Figure 3: Design spectrum utilized. 


\section{Analysis of the results}

The analysis of the 972 parametric models of the elevated water tanks was made using a computational tool called SAP2000 [2]. In order to obtain the maximum responses, the complete quadratic combination rule (CQC) was used [7]. On the basis of this method the total displacements were obtained, as well as the shear forces and bending moments.

The study considered that half of the models to be founded on soil type II and the rest on soil type III (Fig. 3) [7], with the purpose of comparing the interest seismic responses. The validity of this study is limited to the parameters that are adopted by the following dominions: $\mathrm{RR} \in[0.10 ; 0.36] ; \mathrm{HD} \in[2.4 ; 3.2] ; \mathrm{RDE}$ $[1.0 ; 2.7] ; \mathrm{RH}_{\mathrm{c}} \in[0.2 ; 0.4] ; \mathrm{RM} \in[0.9 ; 2.0] ; \mathrm{RH}_{\mathrm{a}} \in[0.35 ; 1.00] ;$ Soil type [2;3].

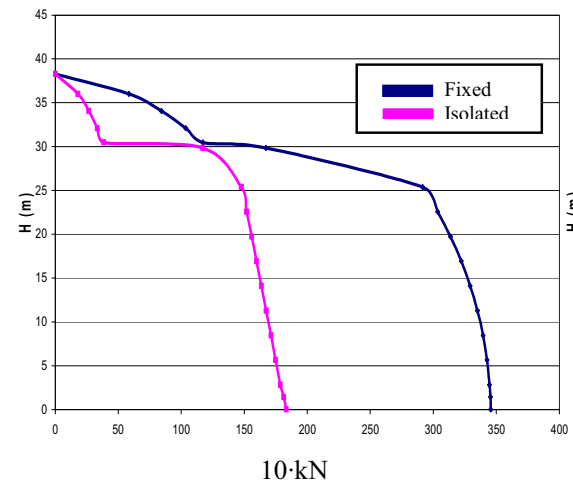

(a)

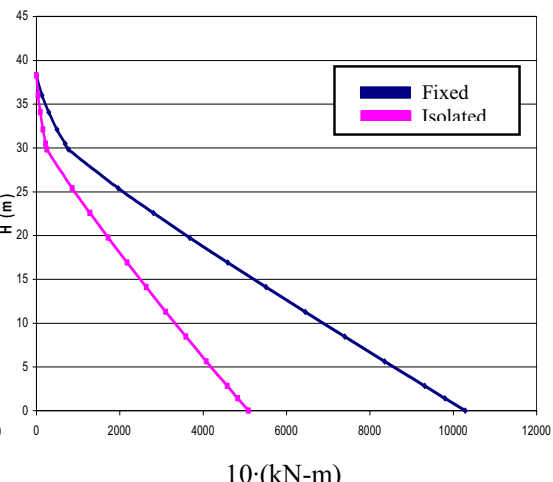

(b)

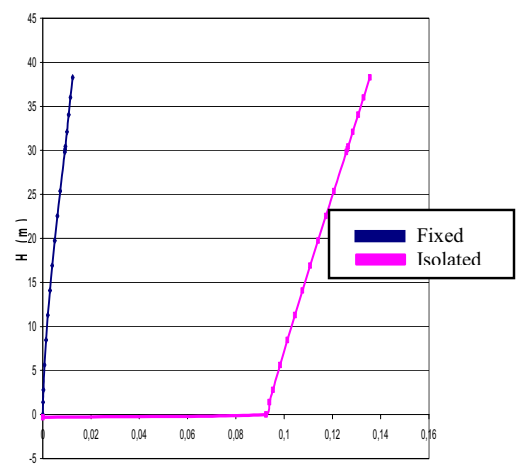

(c)

Figure 4: Seismic responses of the Pointigo-Buin tank: (a) shear forces, (b) bending moments and (c) lateral displacements.

The analysis of results shows the following:

- When comparing the tanks of fixed base with their similar of isolated base were verified that with the incorporation of the isolation device to the 
shear forces (Fig. 4(a)), and the bending moments are reduced in a $50 \%$ (Fig. 4(b)).

- In the cases of fixed and isolated bases, it is demonstrated that the main cause for the abrupt increment of the magnitudes of the shear force is water movement due to seismic excitation.

- The lateral displacement experiments a strong increment of its magnitude in the zone of the isolator that borders $1000 \%$, since the lateral stiffness of this one is considerably smaller for the stiff than it is for the structure of support (Fig. 4(c).

- $\quad$ For the totality of the parametric models, the safety factors of buckling and rollover of the isolators were verified satisfactorily.

\section{Conclusions}

a) When comparing elevated $\mathrm{r} / \mathrm{c}$ tanks of fixed base with their similar of isolated base, it was verified that the incorporation of the isolation device reduces the shear force and the bending moments in 50\%, and although the water stays as the fundamental period of vibration, the isolation system takes the second modal shape of vibration that in the case of the fixed tanks it belongs to the structure (figs. 5, 6).

b) The Chilean code [6] indicates that the relative displacement in all the levels of the structure must be smaller than $2 \%$. For the analysis of the database the tanks fulfill this requirement since the maximum relative displacement was of $1,2 \%$. This means that the tank has a lateral displacement in the form of a rigid body.

c) The incorporation of a system of isolation in the high tanks brings as a consequence that the structure of support presents compressive stress different to the tank that does not consider this flexible fusion that presents tensile effort additionally.

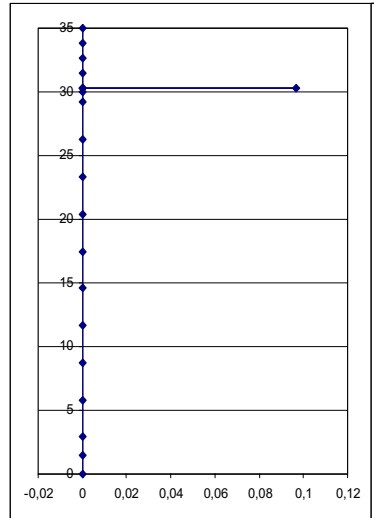

(a)

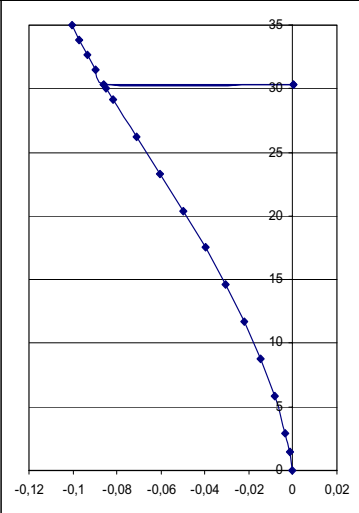

(b)

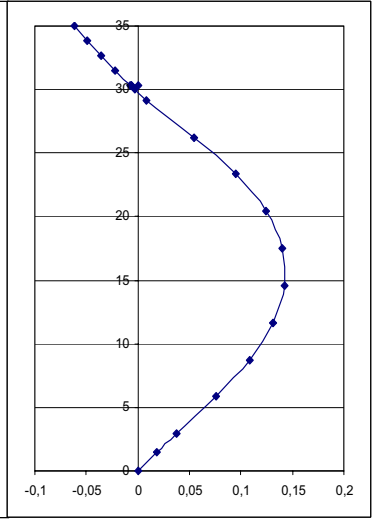

(c)

Figure 5: $\quad$ First three modal shapes of the tank $\mathrm{N}^{\mathrm{o}} 1$ with fixed base and water full: (a) first mode, (b) second mode, (c) third mode. 


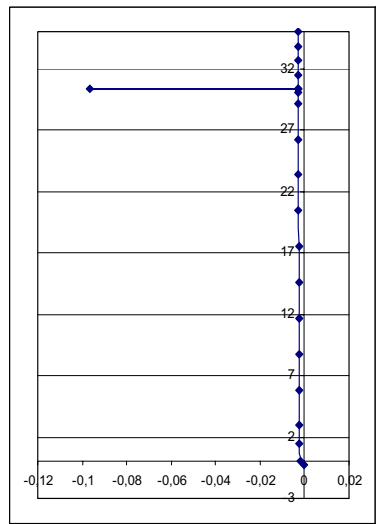

(a)

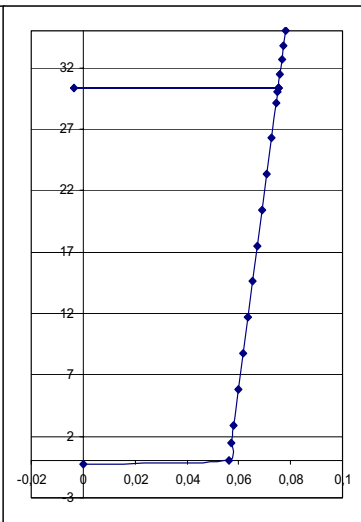

(b)

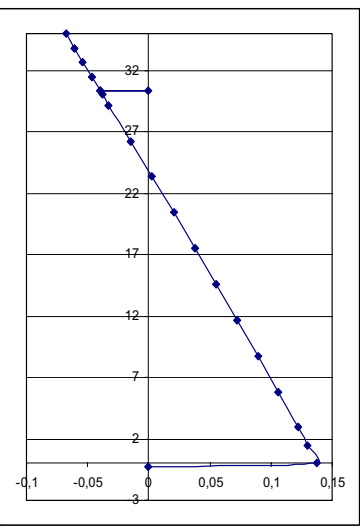

(c)

Figure 6: First three modal shapes of the tank $\mathrm{N}^{\mathrm{o}} 1$ with isolated base and water full: a) first mode, (b) second mode; (c) third mode.

d) The differences of the maximum responses found to the finite element analysis with the analysis of lumped masses using the expressions for the fluid-structure interaction [5] were of $2.3 \%$ in the periods of vibration, of $8.8 \%$ in the lateral displacements, $6.6 \%$ in the basal shear force, and $4.3 \%$ at the bending moments $[1,4]$.

e) The geometric form that acquires the representative outline of the maximum responses of the elevated tanks with isolation is similar to the same structure without isolation. Therefore the seismic behavior of a structure fixes and an isolate is similar, varying only the maximum values.

f) From this one study it is possible to obtain simplified expressions for the analysis of elevated water tanks with seismic isolation in his base [3].

\section{Acknowledgment}

The authors wish to thank the School of Civil Engineering at Civil Works of the Central University, for their support for this investigation.

\section{References}

[1] Baquedano, P., Gran, F., Fernández-Dávila G., V.I. (2006) Methodology for the parametric analysis and seismic design of isolated elevated water tanks. $8^{\text {th }}$ U.S. NCEE. SF, California. USA. April 18-22.

[2] Computers \& Structures, Inc. (2003) SAP2000 Non linear version 8.2 Academic License. Proyecto de Investigación $\mathrm{N}^{\circ} 28$. Universidad Central de Chile. Enero.

[3] Fernández-Dávila G., V.I., Dünner D., R., Carrión P., L. (2005) Simplified Method for Seismic Analysis of Industrial Chimneys. Structural Journal of ACI. 102-S34, Vol. 102, Issue 3, Pp 347-353, May. 
[4] Fernández-Dávila G., V.I., Baquedano, P., Gran, F. (2005) Estudio de la Respuesta Sísmica de Estanques Elevados de Agua de Hormigón Armado con Aislación Sísmica en la Base. IX Jornadas de Achisina. Concepción, Chile. 16-19. Noviembre.

[5] Housner, G.W. (1963) Dynamic Analysis of Fluids in Containers Subject to Acceleration. Bull. Seismology Soc. Am. 47 (1), 15-37.

[6] INN (1996) NCh 433 Of. 96. Diseño sísmico de edificios. Instituto Nacional de Normalización, Santiago, Chile.

[7] INN (2002) NCh 2369 Of.2002 Análisis y diseño sísmico de estructuras industriales. Instituto Nacional de Normalización, Santiago, Chile.

[8] INN (2003) NCh 2745 Of.2003 Análisis y diseño de Edificios con Aislación Sísmica. Instituto Nacional de Normalización, Santiago, Chile.

[9] Muñoz P., M., Fernández-Dávila G., V.I. (2002) Analysis and seismic design of elevated water tanks. $7^{\text {th }}$ U.S. NCEE. Boston, Massachusetts. USA. July $21-25$

[10] Naeim, F., Kelly, J.M. (1999) Design of Seismic Isolated Structures: From Theory to Practice. John Wiley \& Sons, Berkeley, California, USA.

[11] Shenton, H.W., Hampton, F.P. (1999) Seismic response of isolated elevated water tanks. Journal of Structural Engineering. Vol. 125. Issue 9, 965-976. September. 